\title{
Comparative Analysis between the SPIF and DPIF Variants for Die-less Forming Process for an Automotive Workpiece*
}

\section{Análisis Comparativo entre las Variantes SPIF y DPIF del Proceso de Conformado Dieless en una Pieza para Automotores}

\author{
DOI: http://dx.doi.org/10.17981/ingecuc.11.2.2015.07
}

Research Article - Reception Date: May 5, 2015 - Acceptance Date: August 27, 2015

\section{Adrián José Benítez Lozano}

Master in Engineering, EAFIT / University Research Group for Production Technologies, Medellin. (Colombia). abenite2@eafit. edu.co

Gabriel Jaime Páramo Bermúdez

Master in Education and Community Development, EAFIT / University Research Group for Production Technologies, Medellin.

(Colombia).gparamo@eafit.edu.co

Frank Alexander Bustamante Correa

Master in Engineering, EAFIT / University Research Group for Production Technologies, Medellin. (Colombia).

fbustama@eafit.edu.co

To reference paper:

A.J. Benítez Lozano, G.J. Páramo Bermúdez and F.A. Bustamante Correa, "Comparative Analysis Between the SPIF and DPIF Variants for Die-less Forming Process for an Automotive Workpiece," INGE CUC, vol. 11, no. 2, pp. 68-73, 2015. DOI: http://dx.doi.org/10.17981/ingecuc.11.2.2015.07

Abstract- Over time the process of incremental deformation Die-less has been developed in many ways to meet the needs of flexible production with no investment in tooling and low production costs. Two of their configurations are the SPIF (Single point incremental forming) and DPIF (Double point Incremental form. ing) technique. The aim of this study is to compare both techniques with the purpose of exposing their advantages and disadvantages in the production of industrial parts, as well as to inform about Die-less as an alternative manufacturing process. Experiments with the exhaust pipe cover of a vehicle are performed, the main process parameters are described, and formed workpieces without evidence of defects are achieved. Significant differences between the two techniques in terms of production times and accuracy to the original model are also detected. Finally, it is suggested when is more convenient to use each of these.

Keywords - Incremental Sheet Forming, Forming Die, Computerized Numerical Control (CNC), Computer Aided Manufacturing (CAM), Computer Aided Design (CAD) Die-less SPIF-DPIF, Aluminum Alloy 1100
Resumen-A través de los tiempos el proceso de deformación incremental Dieless ha sido desarrollado de numerosas formas a fin de atender las necesidades de producción flexible con nula inversión en herramentales y bajos costos de producción. Dos de sus configuraciones son la técnica SPIF (Single point incremental forming) y DPIF (Double point Incremental forming). El objetivo del presente trabajo es comparar ambas técnicas con el propósito de exponer sus ventajas y desventajas en la producción de piezas industriales, así como dar a conocer a Dieless como un proceso manufacturero alternativo. Se realizan experimentaciones con la cubierta del tubo de escape de un vehículo, se describen los principales parámetros del proceso, y se logran piezas conformes sin evidencias de defectos. También se detectan diferencias significativas entre ambas técnicas en cuanto a los tiempos de producción y exactitud con el modelo original. Finalmente, se sugiere cuándo es más conveniente usar cada una de éstas.

Palabras clave- Deformación Incremental de Lámina, Matriz de Formación, Control Numérico Computarizado (CNC), Manufactura asistida por Computador (CAM), Diseño asistido por Computador (CAD), Dieless SPIF-DPIF, Aleación Aluminio 1100.

* Research article derived from the research project: "Desarrollo y simulación del proceso de conformado de lámina metálica Dieless SPIF - DPIF" Funded by EAFIT University. Starting date: January 20, 2015. Completion date: November $25,2016$. 


\section{INTRODUCTION}

Through the years the achievement of significant savings in time, money, tools and materials has been the justification of industries to do its manufacturing processes more efficient and productive. As proof, in the metal mechanic field, different metal removal processes which have evolved from manual chip removal, drilling, turning and milling into multiple automated machining can be highlighted as part of the developments that have taken place. As for the sheet forming processes, there are methods currently used such as embossing, printing, stamping and punching, among others. However, this modern industry in developed countries shows an innovative method of performing these deformations. This new method is called "Die-less" or incremental forming without die. The creators and literature about it, say it is very useful for the industry because of its many advantages over conventional methods [1], [2], [3]; furthermore, it is a process of numerically controlled incremental forming that may deform sheets of different materials into different forms or complex surfaces [4].

Over the years a wide number of variants of this process have been studied, starting with the introduction of the idea of incremental forming in 1960 by Roux and Leszak [5], [6]. Iseki, Kato and Sakamoto [7] have proposed incremental forming at a single point SPIF (single point incremental forming) in which a round tipped tool with a predefined path used in a CAM (computer aided manufacturing) environment for forming, in this case there is only contact between the tool tip and the metal sheet hence its name. Matsubara [1] proposed the incremental forming at two points DPIF (double point incremental forming); in this process, besides having a spherical tool, there is a die having the final shape of the workpiece so that the metal sheet makes contact at two points, one given point between the die and the sheet and the other point between the tool and the sheet. In particular, this article will focus on the comparison of these two processes.

In this research, it is intended to introduce Die-less, with its variants SPIF and DPIF, as a process of great industrial impact for parts, prototypes and short production runs in metal sheet. This would be useful for the metal mechanic sector, because if the characteristics of productive configuration allow it, it is possible to enjoy certain advantages that are inferred throughout this work. Furthermore, scientific and social impact would be notable, since the analysis and comparison of variants SPIF and DPIF have not been specifically addressed in the scientific community with a case of industrial development, which is studied in this work.

\section{Materials and Methodology}

Both processes, SPIF-DPIF (Fig. 1), are based on the design of a geometry in a computer-aided design or CAD system; that geometry will be the final form the sheet will take when both processes are carried out. After this step, the respective simulation of the manufacturing process is performed on a computer aided manufacturing system CAM, which will result in the various paths that the tool will follow.

This tool will be pressing and deforming the material to bring it to its plastic zone so that it does not have a subsequent elastic recovery and it could end with as previously defined shape by the CAD system. Finally, the metal sheet is mounted in a milling center CNC (computer numerical control) of three axes; and with the help of a support that allows stabilizing the process, and then the respective parameters and G-codes are programmed.

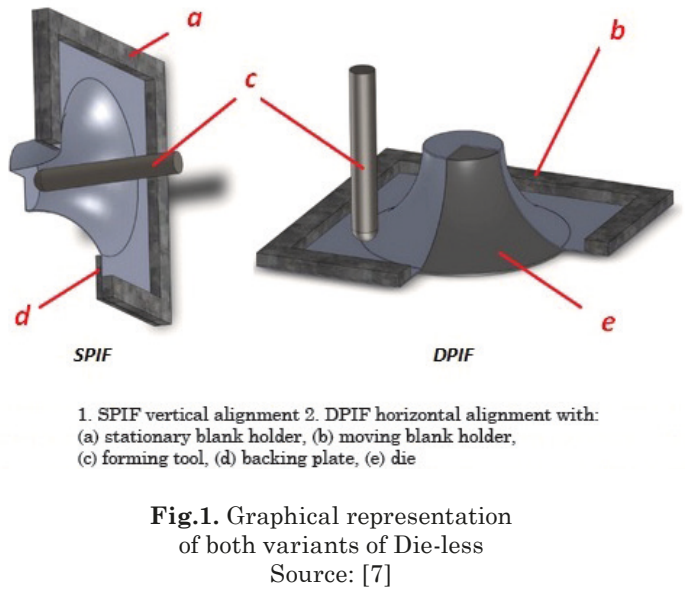

The difference between the two processes lies in the construction of a die [8] with defined geometry for the DPIF process. This generates more time in the process development from its conception until obtaining its geometry.

\section{A. SPIF variant}

For the experimental SPIF case and as the starting point, an industrial part of the auto part sector was taken, in particular, the cover of a motorcycle exhaust pipe, which was provided by a manufacturing company (Fig. 2).

This part was subjected to a first analysis in a CAD system in order to check its viability and implementation; the possible angles of formability were verified and compared with those recommended by the literature [9], in addition, an oversize CAD model was made, corresponding to an offset that matches the diameter of the tool to avoid dimensional errors in the shaping of the part. 


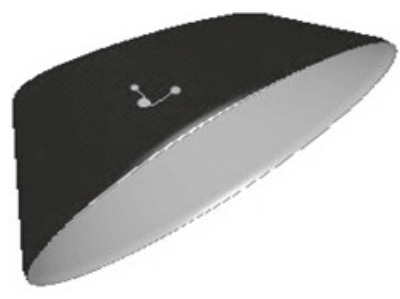

Fig. 2. Industrial part of the auto parts sector, SPIF and DPIF case. Source: Author

Through a CAM system, a path by horizontal planes was made, which aimed to show the deformation path to be followed by the tool. This path is shown in Fig. 3.

The used supply was an aluminum foil 1100 of dimensions $310 \mathrm{~mm}$ x $310 \mathrm{~mm}$ with a thickness of 1 $\mathrm{mm}$. Accordingly, the various parameters were calculated and the mounting of the sheet on a SPIF specialized device was carried out in a machining center located in the manufacturing laboratory of EAFIT University.

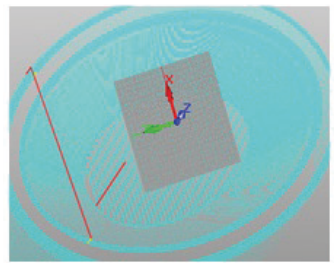

CAM-SPIF tool path

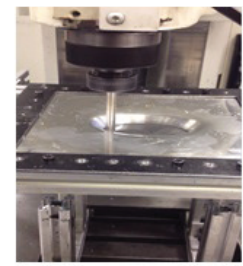

SPIF process
Fig. 3. Tool paths and Simulation of SPIF variant Source: Author

\section{B. DPIF Variant}

For the experimental DPIF case, the industrial part taken for the development of the experiment was the same that served as a starting point in the SPIF process. As stated earlier, the most significant difference between the two techniques lies in the construction of a die or mold with the geometry to be developed. This die, which is shown in Fig. 4, was designed and manufactured in a CAM system from the industrial part shown in Fig. 2. As a next step, the cavity machining is performed on a CNC machine found at EAFIT University. As a construction supply, it was used an MDF wood block with dimensions 170 x 110 x $83 \mathrm{~mm}$.

After the die construction, the tool paths were modeled in the same CAM software used in the SPIF process. These tool paths were also made through horizontal planes as shown in Fig. 4.

As supply, it was used the same material in the SPIF process: 1100 aluminum foil with dimensions $310 \mathrm{~mm} \times 310 \mathrm{~mm}$ and thickness of $1 \mathrm{~mm}$.

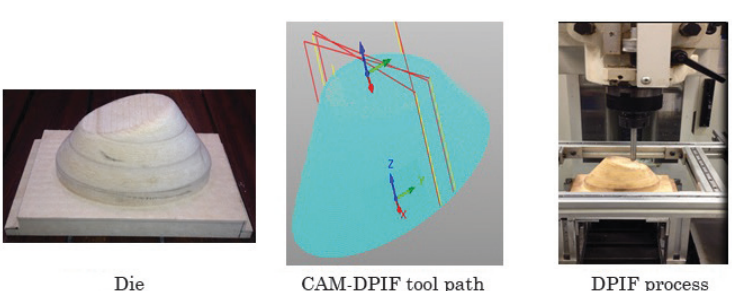

Fig. 4. Tool paths, simulation and DPIF variant process Source: Authors

Finally, calculation of the various parameters were made, the assembly of the sheet and the die in a specialized DPIF device was run and the same machining center was used as in the SPIF process, as shown in Fig. 4.

\section{Parameters, Variables and tools used in Die-less process and its variants (SPIF-DPIF)}

The variables and parameters used in the experimentation and development that are common to both processes are listed below (Table I). These variables were obtained by previous research of Dieless process and have shown that the speed of the machine spindle, tool feed rate, the depth of cut, the formability angle and the tool affect this process in a critical way [2].

\section{1) Spindle Speed (RPM)}

It refers to the speed at which the tool rotates. This depends on factors like the machinability of the material, hardness and type of surface finish among other things. For the particular case of the tests, values of $2000 \mathrm{RPM}$ were used, since the literature recommends not exceeding those values. [10].

\section{2) Tool Feed Rate}

It is the relative speed that occurs between the tool and the workpiece [2]. After the tool finishes its first tour, it performs an increase between planes; if this increase is minimal the geometry of the final workpiece will have better surface finishes. For the case study we worked with values of $500 \mathrm{~mm} / \mathrm{min}$.

\section{3) The Depth of Cut}

It refers to the depth to which the tool enters the workpiece and generates a chip removal on the surface in each pass. For this case, a $1.0 \mathrm{~mm}$ cut was made. It is clear that in both processes there is no chip detachment; as these processes rely on a material deformation tool with a spherical tip, thus the increases only occur in the z-axis of the abovementioned value. 


\section{4) Formability Angle}

These angles are given by the geometry of the workpiece and so far it has been found that they cannot exceed $68^{\circ}$ [9], [10]. If this value is exceeded, cracks and wrinkles will occur in the material [11], [12], [13], [14]. As stated above, all angles of the workpiece were analyzed and compared with those recommended in the literature and it was concluded that there was no angles that exceeded the aforementioned limit; therefore, geometry was suitable for development in both processes.

\section{5) Tool}

The tool used in both variants is a milling cutter of $10 \mathrm{~mm}$ diameter with a steel spherical tip 4340 with heat treatment of 5 tenths of depth cementing. It is recommended that the diameter of the tool be up to 10 times the thickness of the metal sheet [4] [10].

Table I. Parameters Used For Spif-Dpif Variants

\begin{tabular}{|c|c|}
\hline \multicolumn{2}{|c|}{ Parameters used in SPIF- DPIF processes } \\
\hline Spindle speed (RPM) & 4000 \\
\hline Feed rate (mm / min) & 2000 \\
\hline Depth of cut (pass) (mm) & 1.0 \\
\hline Formability angles & $>68^{\circ}$ \\
\hline Tool diameter (mm) & 10 \\
\hline
\end{tabular}

Source: Author

For measurements of thicknesses, different measurements are taken in each of the different areas of the workpiece; it is done with specialized external micrometers previously calibrated. For the particular case, one measuring range between 0 and 25 $\mathrm{mm}$, with $0.01 \mathrm{~mm}$ scale division is used; the uncertainty is $\pm 0.01 \mathrm{~mm}$ which determines the tolerance or allowable range in which the taken measurements are contained.

\section{III.Results AND Discussion}

In Fig. 5 are shown the machining steps and the final workpiece obtained by the DPIF process. Visible to the naked eye, there are very good results in terms of final formability. The workpiece got a good surface finish where no cracks or wrinkles are observed.

Machining steps performed by the SPIF process are shown in Fig. 6. Similarly the DPIF process, a workpiece that visibly meets the requirements of formability was obtained. Additionally, no cracks or wrinkles are observed in the machined surface and its surface finish is accepted.

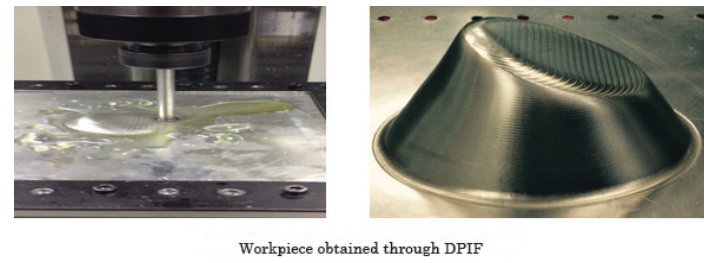

Fig. 5. Machining and workpiece obtained through DPIF variant Source: Author

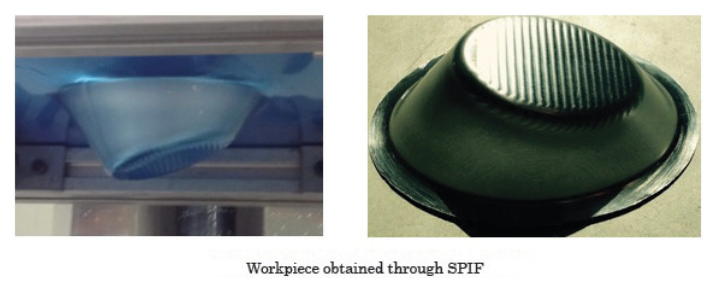

Fig. 6. Machining and obtained workpiece through SPIF variant Source: Author

As for the surface finish in both processes, it should be said that it can be improved with the variation of the parameters described above with emphasis on the feed rate and depth of cut, since these parameters when taking lower values, make the surface quality thinner and detailed.

Table II shows a comparison table with the most important variables that were taken into account in both processes with their respective values.

Table II. Parameters Used for Spif-Dpif Variants

\begin{tabular}{|c|c|c|}
\hline \multicolumn{3}{|c|}{ COMPARISON SPIF vs. DPIF } \\
\hline Assembly time & 40 min & 1.5 hours \\
\hline Die & Not necessary & Necessary \\
\hline Die machining time & 0 hours & 2.5 hours \\
\hline Manufacturing time & 23.8 min & 30.25 min \\
\hline Calibration die-sheet & Not necessary & Necessary \\
\hline Calibration time die-sheet & 0 min & 15 min \\
\hline Formability & Accepted & Accepted \\
\hline Measuring accuracy & Variable & Successful \\
\hline Machining & Negative & Positive \\
\hline Surface finish & Accepted & Accepted \\
\hline Device use & Necessary & Necessary \\
\hline Coolant use & Oil & Oil \\
\hline Cracks and / or wrinkles in & Not observed & observed \\
\hline
\end{tabular}

Source: Author 
Both processes have significant differences in their execution times. These differences become greater due to the production and use of the die in the DPIF process. As shown in Table II, the test performed in the SPIF process presents assembly and machining times of 40 and 23.8 minutes respectively. For the DPIF process, these times, were 1.5 hours and 30.25 minutes respectively, besides these times, this process also exhibits the die machining times and its calibration values of 2.5 hours and 15 minutes, respectively, which are not present in the SPIF process.

Although the SPIF process shows better times compared to the DPIF process, the latter is of great importance considering an evaluation of the dimensional accuracy, which is the preservation of the measures of the original model in the finished workpiece. As noted in the course of the experiment, using the DPIF technique, the original measurements of the part are respected due to the use of the die with the geometry developed in a positive way, the tool can support the sheet against it, so it takes the defined form; as a result an exact copy of the original part is obtained.

Conversely, failure to use a die with SPIF technique results in an undersized workpiece, this is due to the elastic recovery property of the material, since it tends to easily springback after deformed when being held in vacuum and negatively; due to this phenomenon, it is more difficult to find an optimal path to allow a minimum variation of the measures of the final workpiece in relation to the original model. This aspect could be improved if a prior oversizing of the original CAD model of the workpiece is made in order to take into account this under-sizing phenomenon and thus obtain a workpiece with the required actual dimensions. However, it was observed in experiments that even realizing the oversizing to the target workpiece in the SPIF process, this workpiece does not present the same level of forming obtained with the DPIF process.

Accordingly, for industrial processes in which accuracy and precision of the measurements of the final workpiece in respect to the original model are important, it becomes more attractive the use of the DPIF process even if this means higher manufacturing and assembly times. In contrast to processes in which lead times and production take precedence, the Die-less method through SPIF variant could be taken into consideration.

It is well known that the geometric precision and accuracy of the workpiece is much better for the DPIF variant than for the SPIF variant. Many authors confirm this fact in their experiences and work carried out, where several experiments with these techniques, including finite element analysis and FLD curves reflect the degree of forming of the workpiece [15], [16] and [17]. The experience gained from this work is not far from the previous statement.

Another variant of Die-less process may add to the two mentioned and studied in this work (SPIFDPIF) is the incremental deformation on both sides of the workpiece - Double Side Incremental Forming (DSIF), in which the deformation process occurs by two synchronously working tools on either side of the workpiece. This variant also ensures better results in accuracy and dimensional accuracy than the SPIF technique [16]. A comparison between DSIP and the TPIF variant, in which the results are valued, is worthwhile.

The workpieces obtained by both processes did not evidence breakage at any point of the material, in addition to this; a good surface finish is also appreciated, leading to the conclusion that the workpieces had a high degree of forming.

Now that we have evaluated the possible causes that would generate the use of both processes separately, and each with its advantages and disadvantages; It is intended to investigate on the joint use of both processes as hypotheses for future research aiming at more complex geometries, understanding the complexity of the workpiece including both variants, in which its design requires both negative and positive cavities and allow further studies of all variables to consider for both processes. Also, it is necessary for immediately subsequent work to carry out depth studies of measurements, roughness, microstructure, hardness and / or ultrasound in order to make a larger and enriching scientific contribution to both variants of the Die-less process, and thus continue arguing its applicability and increasingly strengthen the industrial feasibility of this process.

Additionally, it is the intention of this paper to motivate the reader to continue exploring on the Die-less method and the different ways of being developed, all in order to examine its advantages over conventional methods.

\section{CONCLUSIONS}

Thanks to its flexibility, low cost and savings in tool expenses, It has been found that the process of incremental forming Die-less in two variants (SPIF- DPIF) can be an effective alternative in the production of various high costs geometries that force companies to justify high production volumes. In addition, the ease of prototyping is a strong competitive advantage over conventional processes because the modifications to be made in the original model are virtually run by the CAD-CAM platform, resulting in significant savings in the absence of building a new die for each model modification. Jointly, human error is reduced because accuracy is achieved by only entering the correct parameters and not by the expertise of the operator. 
For both (SPIF-DPIF) variants of the Dieless technique, there was no presence of cracks or fractures affecting the surface quality of the workpieces obtained, demonstrating the plasticity of the material, i.e., the ability to plastically get deformed by a succession of points in space generated by the CAM strategy for both processes. This fact explains to a large extent, the applicability of the process to endless parts obedient to geometries near an industrial principle in the auto and motorcycle parts industry.

The SPIF variant has been widely studied, but still the desired rigorous dimensional accuracy in an industrial application that meets the strict control of dimensional quality [18] has not been obtained, which makes this variant to have a huge disadvantage with fewer opportunities for development and study in respect to the DPIF variant.

Die-less forming process was developed in Japan as a flexible manufacturing method, as an alternative to stamping and deep drawing, in order to produce parts in batches or short production runs. It is an incremental forming process that is numerically controlled and which can deform various materials into complex shapes. It can be extremely profitable, since no conventional tooling is required and the waiting time is significantly reduced [4]. Currently, incremental forming technology is attracting attention as an effective method for rapid prototyping and small production.

\section{REFERENCES}

[1] S. Matsubara, "Incremental Backward Bulge Forming of a Sheet Metal with a Hemispherical Head Tool," J. J.S.T.P., vol. 35, no. 406, pp. $1311-1316,1994$.

[2] G. Páramo Bermúdez and A. Benítez Lozano, "Deformación incremental de lámina sin matriz (DIE-LESS) como alternativa viable a procesos de conformación de lámina convencionales," INGE CUC, vol. 9, no. 1, pp. 115-128, Jul. 2013.

[3] A. García and G. Páramo, "Análisis del comportamiento y caracterización del Single Point Incremental Forming" utilizando tecnología de control numérico para un caso de estudio en un componente del mobiliario de exteriores", M.S thesis, Dept. Ing. Mec., Univ. EAFIT, Medellín, Colombia, 2011

[4] M. Amino, M. Mizoguchi, Y. Terauchi, and T. Maki, "Current Status of 'Die-less' Amino's Incremental Forming," Procedia Eng., vol. 81, pp. 54-62, 2014. DOI: 10.1016/j. proeng.2014.09.128
[5] P. Roux, "Machine for shaping sheet metal," US2945528 A, 14-Jan-1960.

[6] E. Leszak, "Apparatus and process for incremental dieless forming," US3342051 A, 19-Sep-1967.

[7] H. Iseki, K. Kato, And S. Sakamoto, "Flexible and Incremental Sheet Metal Bulging using a Path-Controlled Spherical Roller.," Trans. Japan Soc. Mech. Eng. Ser. C, vol. 58, no. 554, pp. 3147-3155, Jan. 1992. DOI: 10.1299/kikaic.58.3147

[8] I. Paniti, "A novel, single-robot based two sided incremental sheet forming system," in 45th International Symposium on Robotics, ISR 2014 and 8th German Conference on Robotics, ROBOTIK 2014, pp. 547-553, 2014.

[9] P. Gabriel and B. Adrian, "Developing an experimental case in aluminum foils 1100 to determine the maximum angle of formability in a piece by Die-less-SPIF process," IOP Conf. Ser. Mater. Sci. Eng., vol. 65, no. 1, p. 1-10, Jul. 2014. DOI:10.1088/1757-899X/65/1/012027

[10] S. Arango Botero and P. Arena Espinosa, "Estudio del comportamiento de lámina metálica en el proceso incremental die-less forming en dos puntos de apoyo (herramienta y molde),” M.S thesis, Dept. Ing. Prod., Univ. EAFIT, Medellín, Colombia, 2011

[11] S. Kalpakjian and S. R. Schmid, Manufactura, Ingeniería y Tecnología, 5th ed. Mexico:Pearson, 2008.

[12] W. Smith, Ciencia e ingeniería de materiales, 3rd ed. España: McGrawHill, 2004.

[13] T. B. Stoughton and J. W. Yoon, "A new approach for failure criterion for sheet metals," Int. J. Plast., vol. 27, no. 3, pp. 440-459, Mar. 2011. DOI: 10.1016/j.ijplas.2010.07.004

[14] C. Vallellano, D. Morales, A. J. Martinez, and F. J. Garcia-Lomas, "On the Use of Concave-Side Rule and Critical-Distance Methods to Predict the Influence of Bending on Sheet-Metal Formability," Int. J. Mater. Form., vol. 3, no. S1, pp. 1167-1170, Jun. 2010. DOI: 10.1007/s12289-010-0980-0

[15] M. B. Silva and P. A. F. Martins, "Two-Point Incremental Forming with Partial Die: Theory and Experimentation," J. Mater. Eng. Perform. vol. 22, no. 4, pp. 10181027, Oct. 2012. DOI: 10.1007/S11665-012-0400-3

[16] J. H. Wu and Q. C. Wang, "Comparison of the Geometric Accuracy by DSIF Tool-path with SPIF Tool-path," Appl. Mech. Mater., vol. 494-495, pp. 497-501, Feb. 2014.DOI: $\quad$ 10.4028/www.scientific.net/AMM.494495.497

[17] J. Smith, R. Malhotra, W. K. Liu, and J. Cao, "Deformation mechanics in single-point and accumulative double-sided incremental forming," Int. J. Adv. Manuf. Technol., vol. 69, no. 5-8, pp. 1185-1201, Jun. 2013. DOI: 10.1007/S00170-013-5053-3

[18] C. Radu, I. Cristea, E. Herghelegiu, and S. Tabacu, "Improving the Accuracy of Parts Manufactured by Single Point Incremental Forming," Appl. Mech. Mater., vol. 332, pp. 443-448, Jul. 2013. DOI: $10.4028 /$ www.scientific.net/AMM.332.443 